Supporting Information

For

\title{
Separation of Linearly Aligned Five Carbons into Two-carbon and Three-carbon groups on Titanium
}

Zhiyi Song, Yi-Fang Hsieh, Kiyohiko Nakajima, Ken-ichiro Kanno and Tamotsu Takahashi* Institute for Catalysis, Hokkaido University, Kita 21, Nishi 10, Kita-ku, Sapporo 001-0021, Japan and Department of Chemistry, Aichi University of Education, Igaya, Kariya, Aichi, 448-8542, Japan 


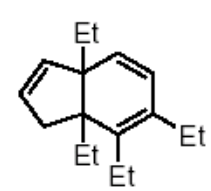

$4 a$
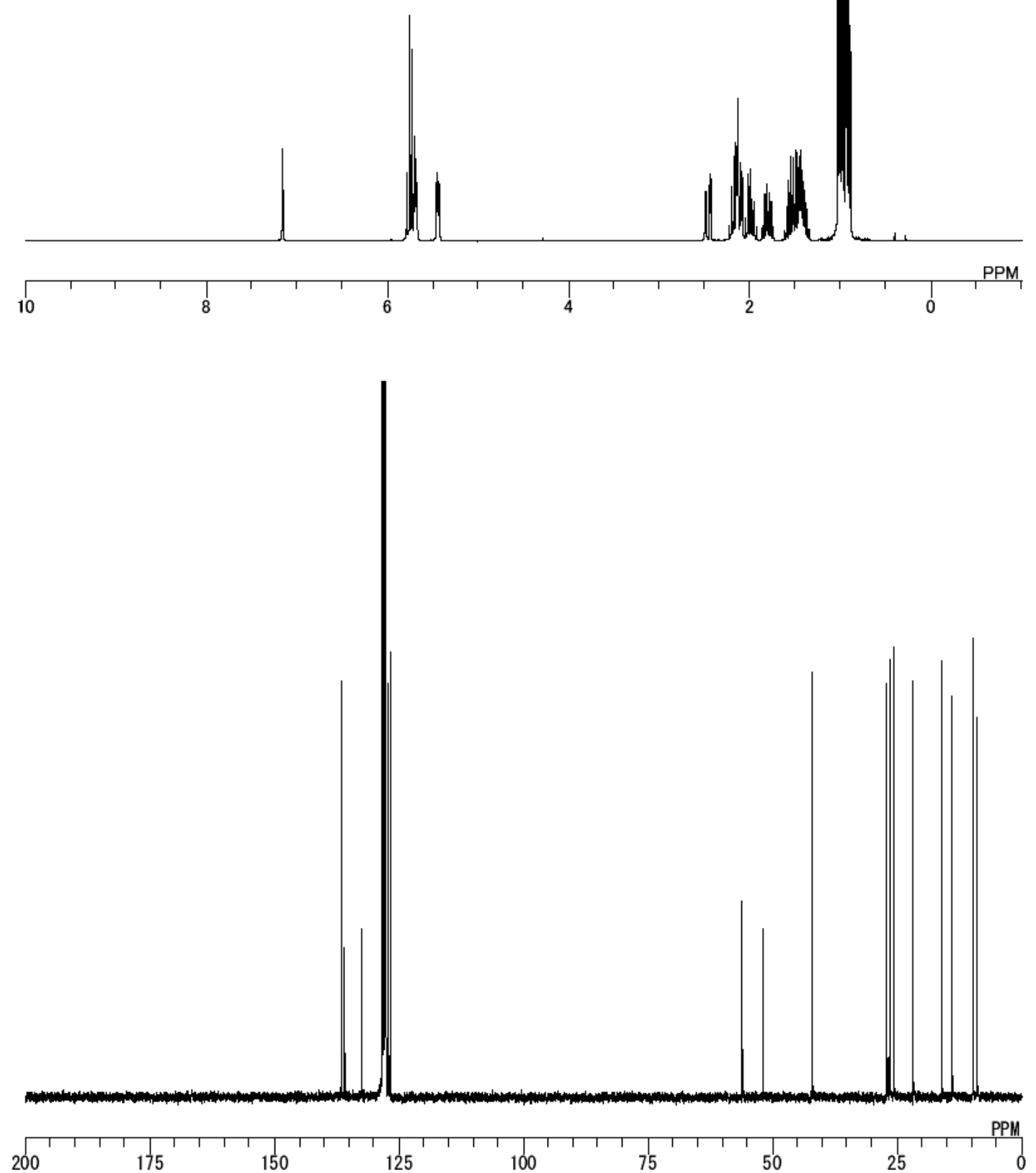

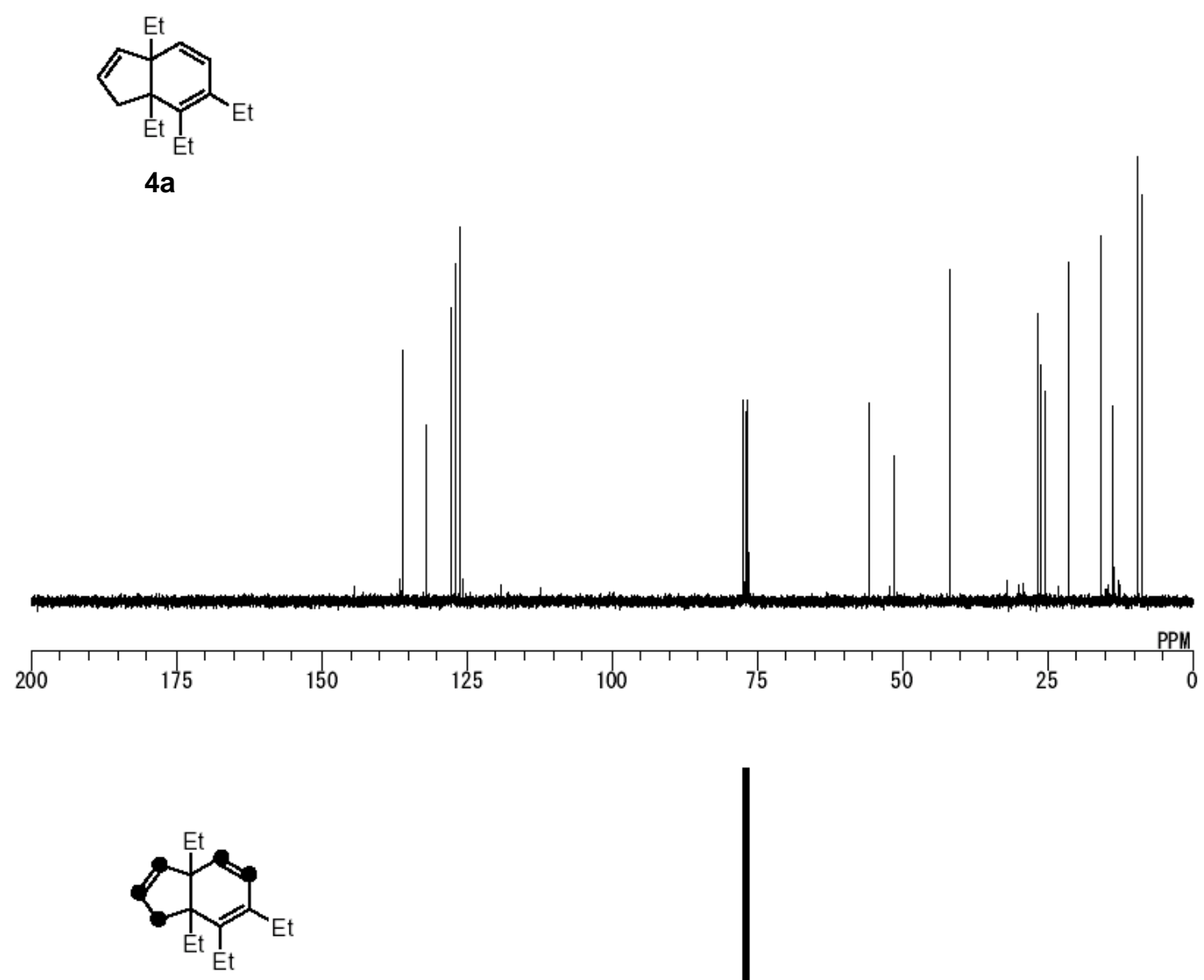

$4 a-{ }^{13} \mathrm{C}$

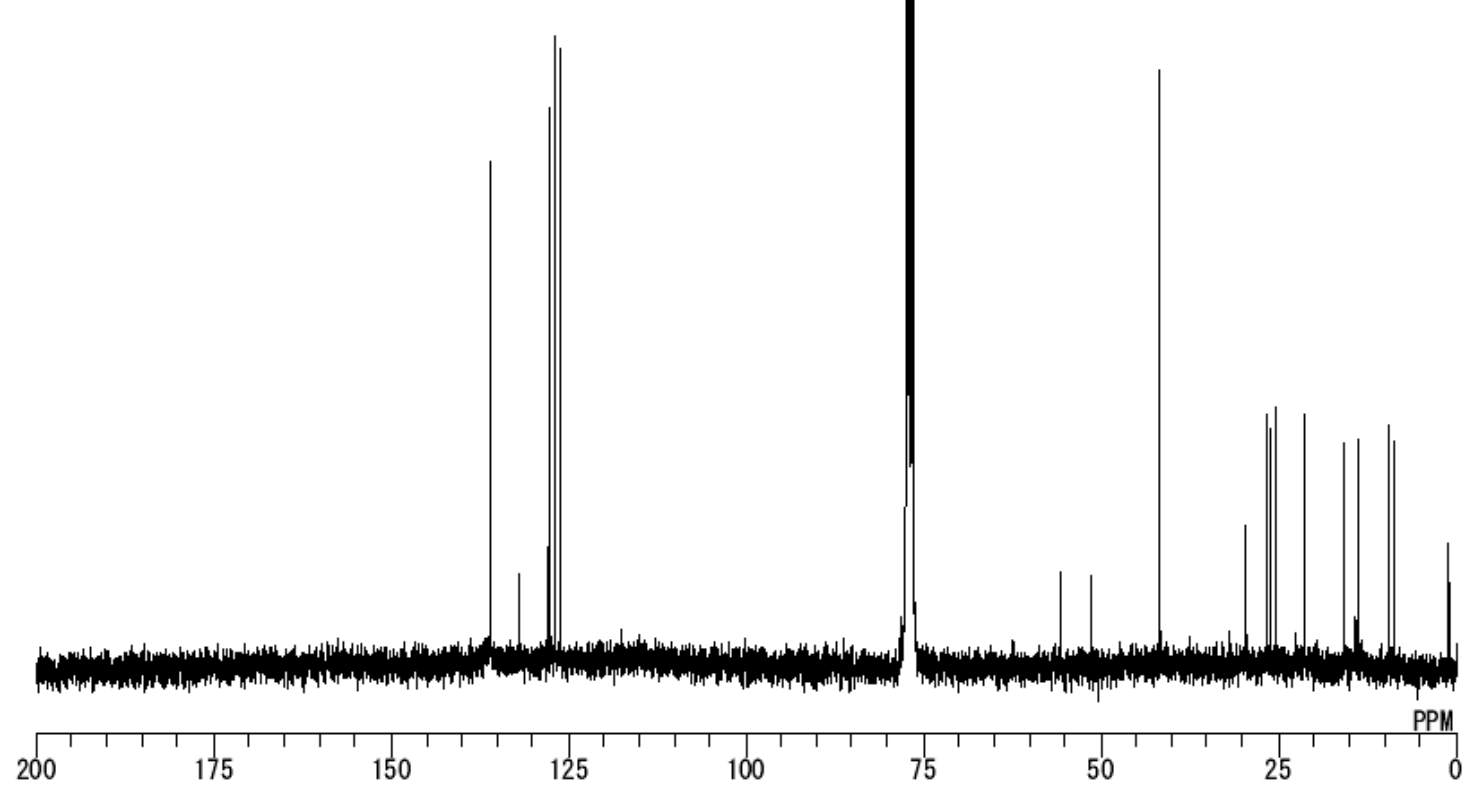



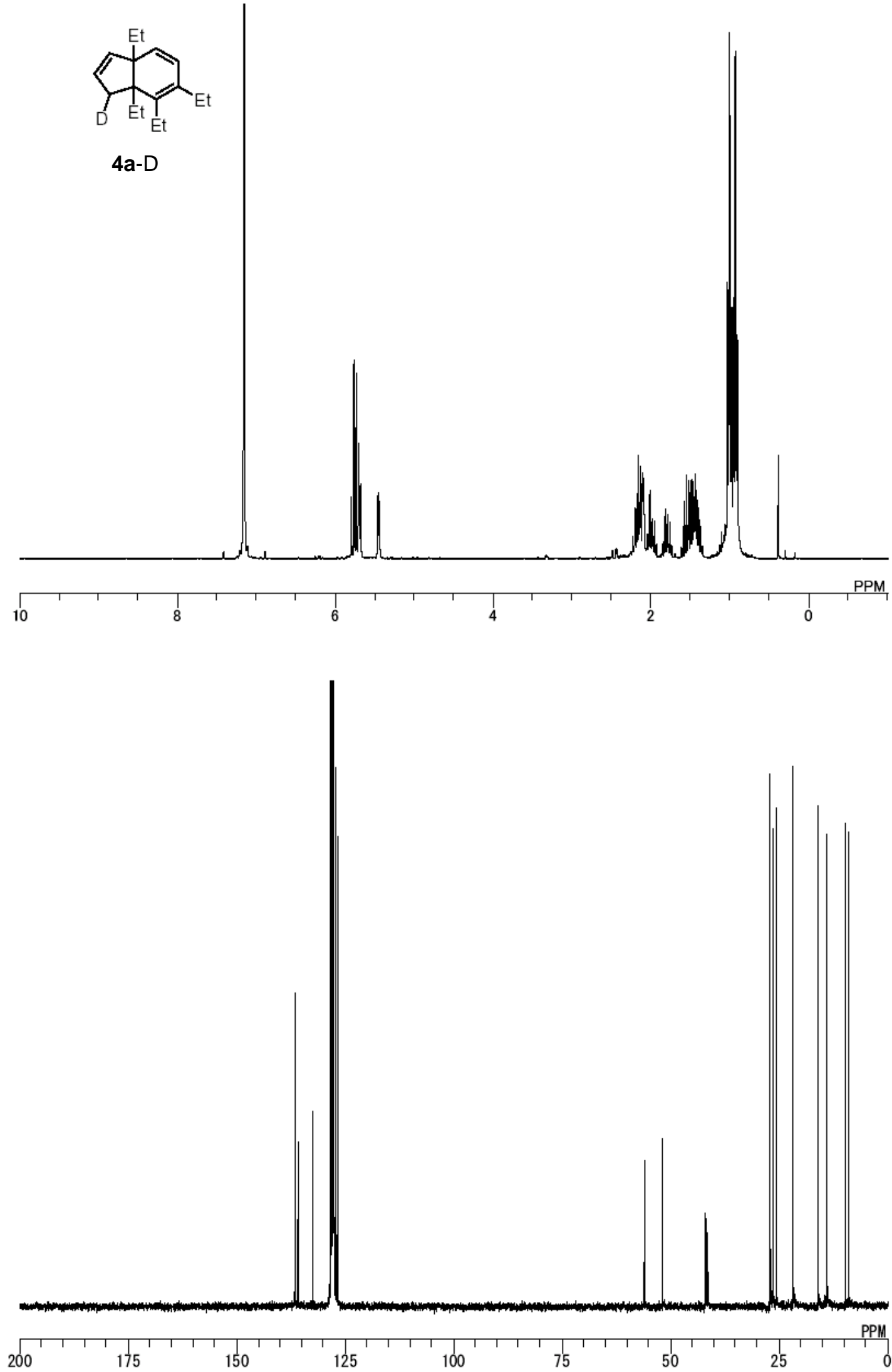

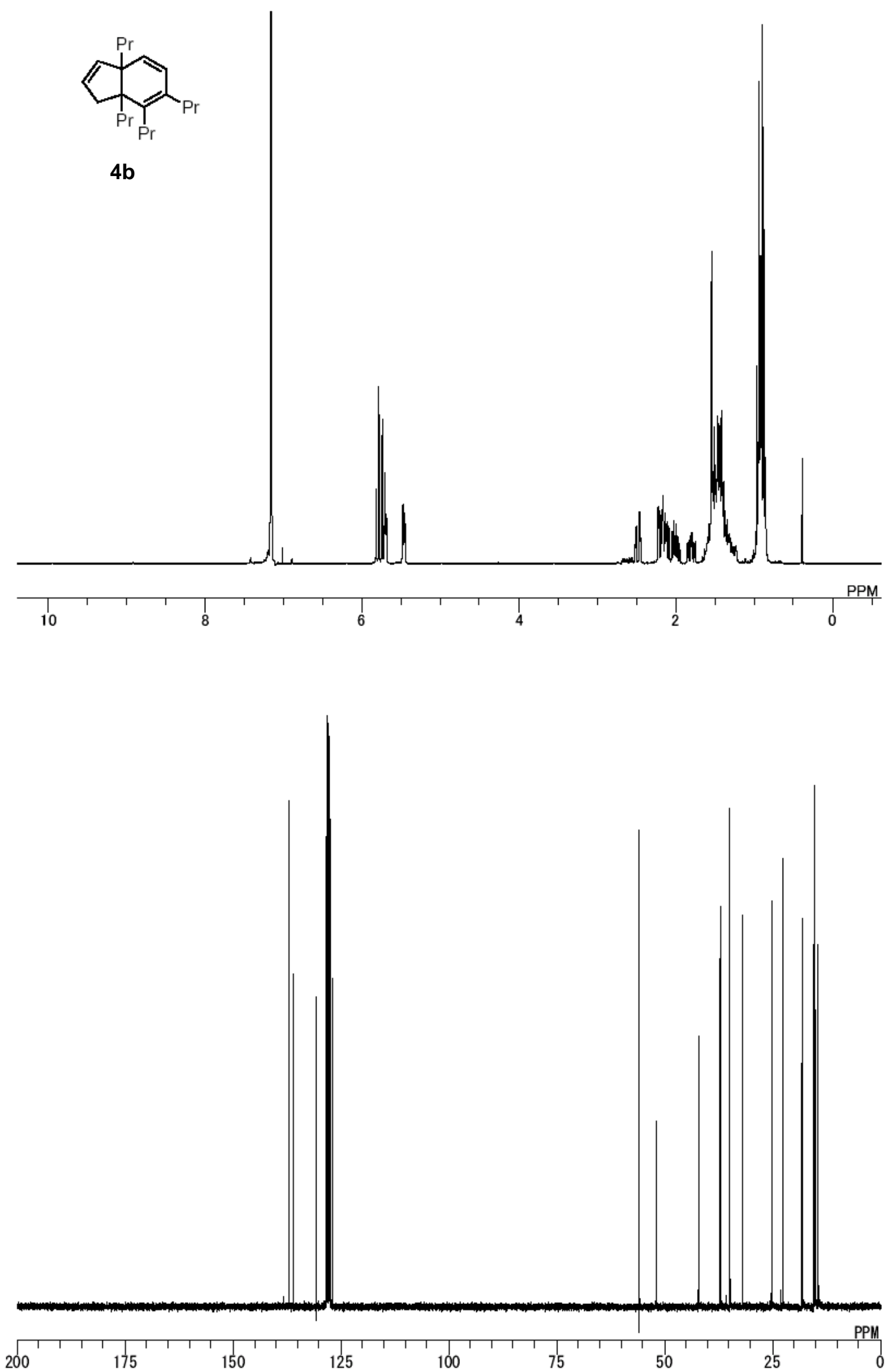


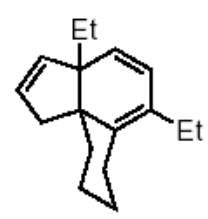

4c
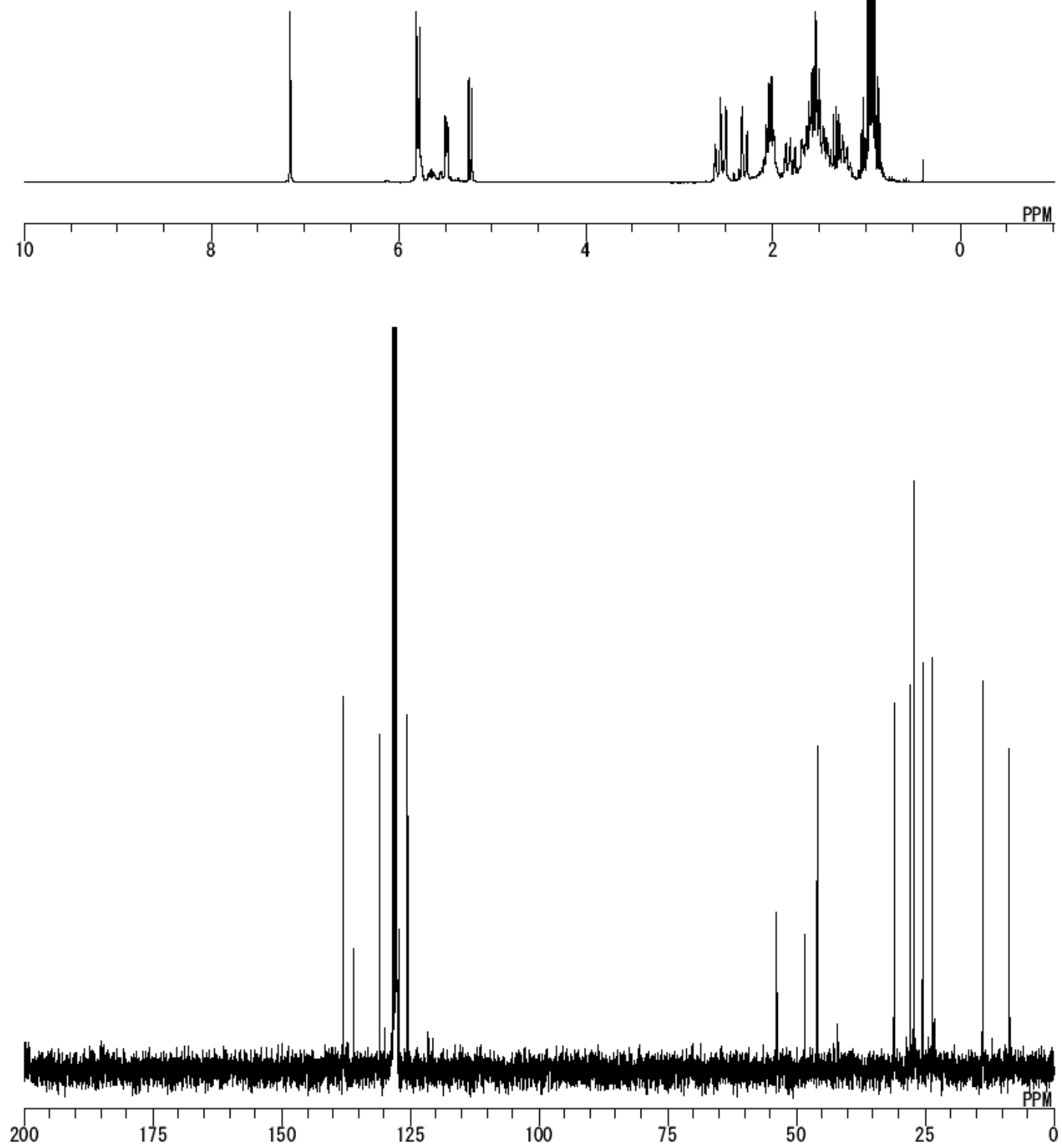

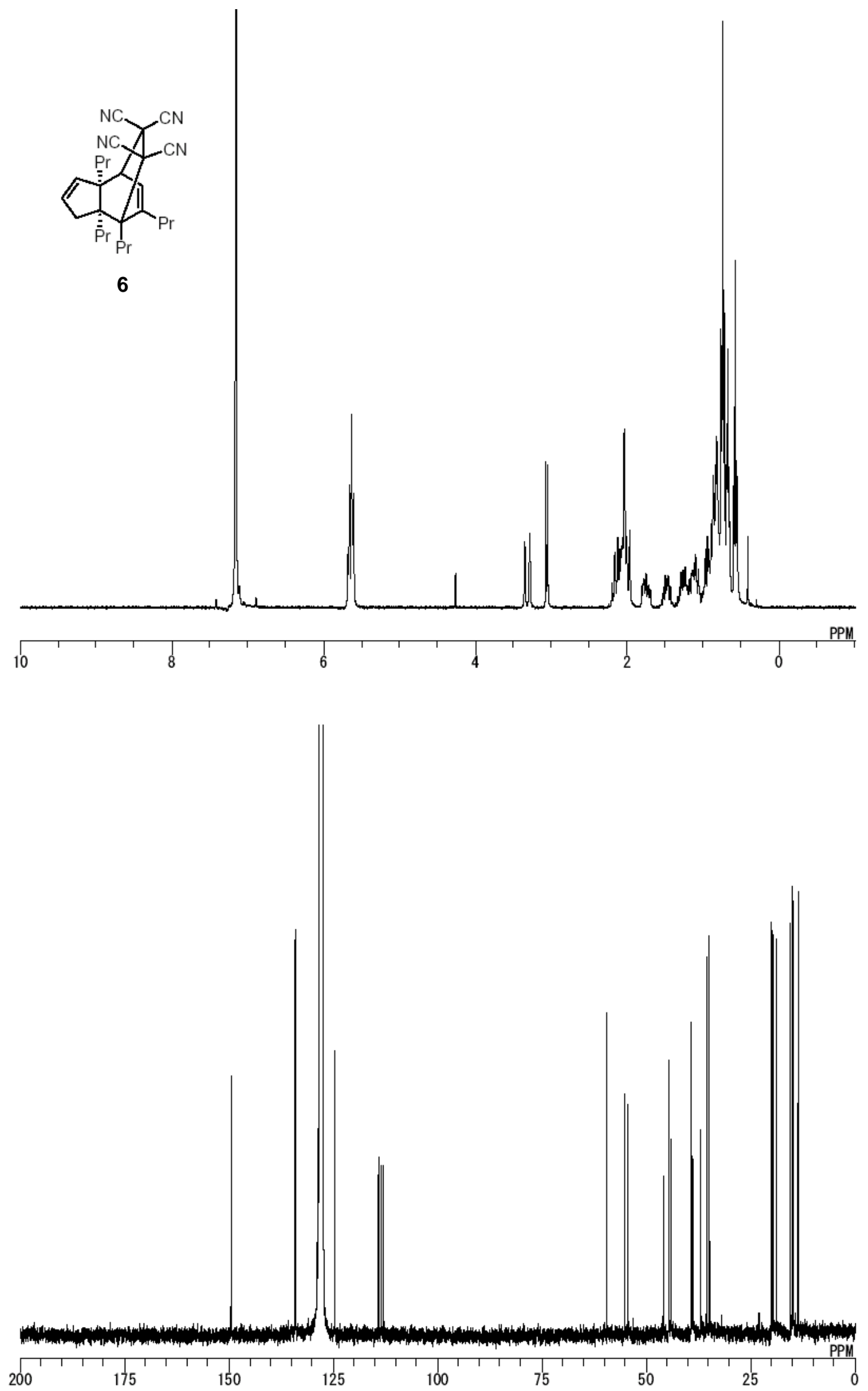

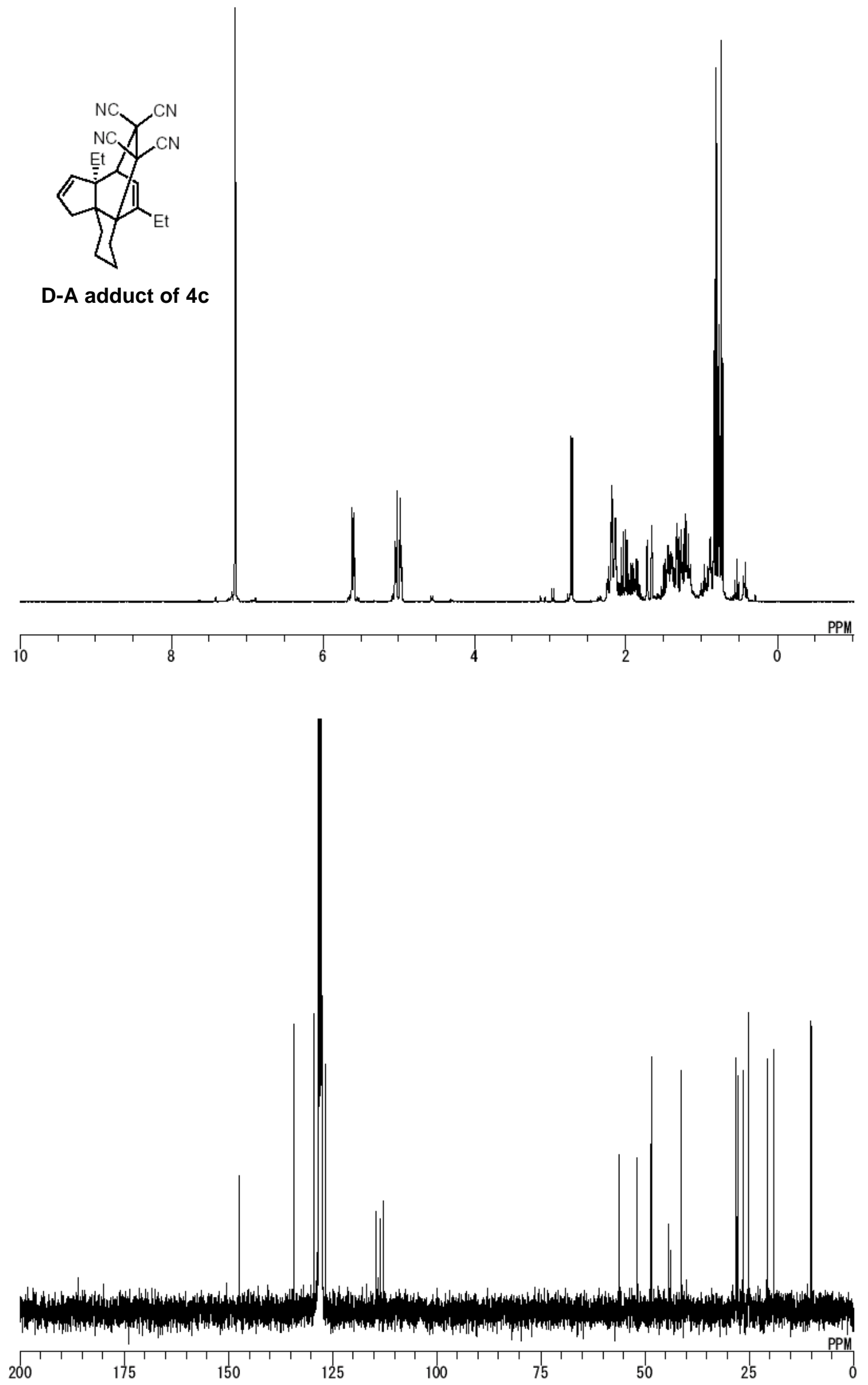

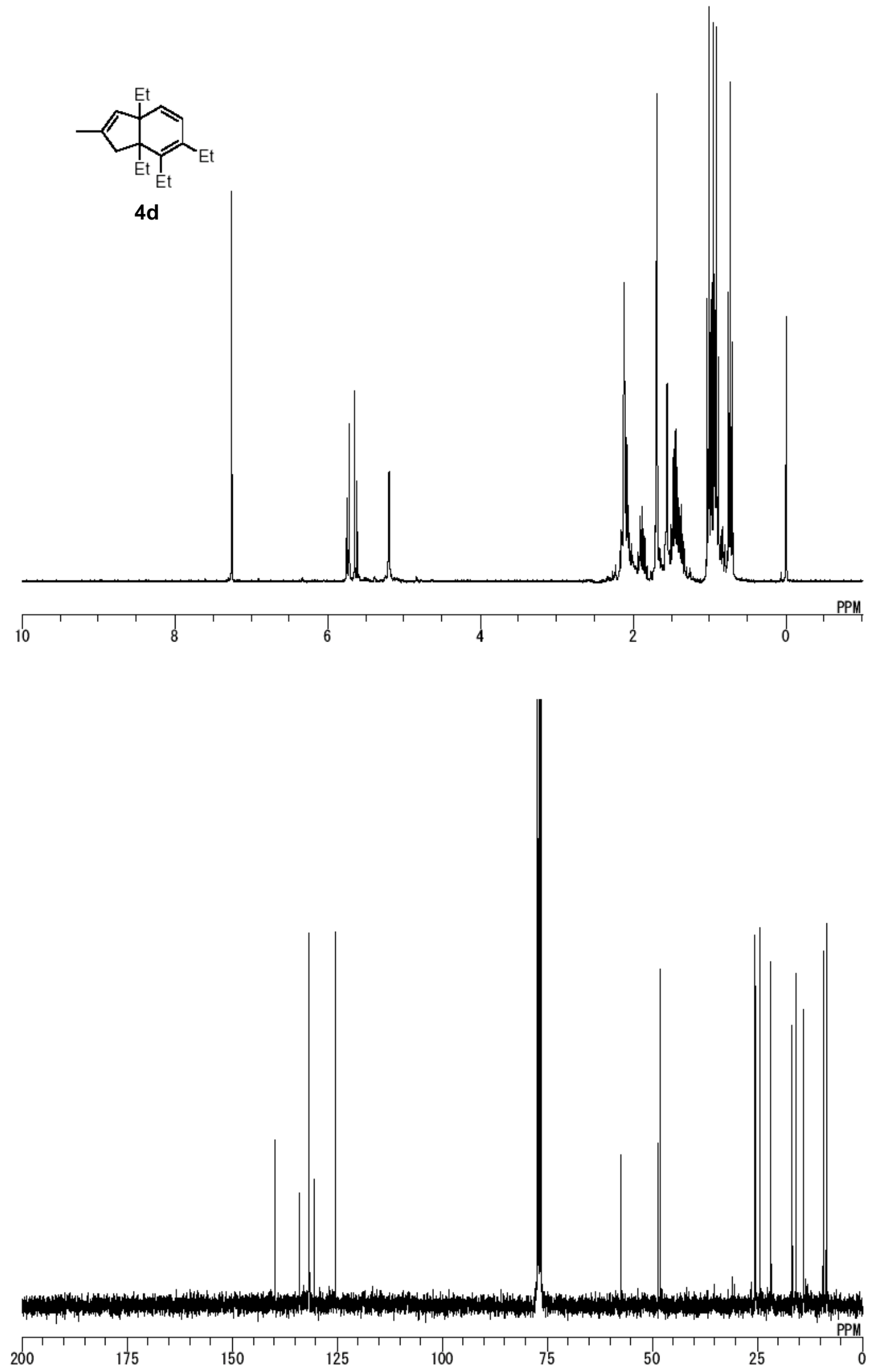

S9 


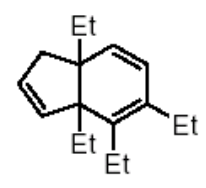

$4 a^{\prime}$
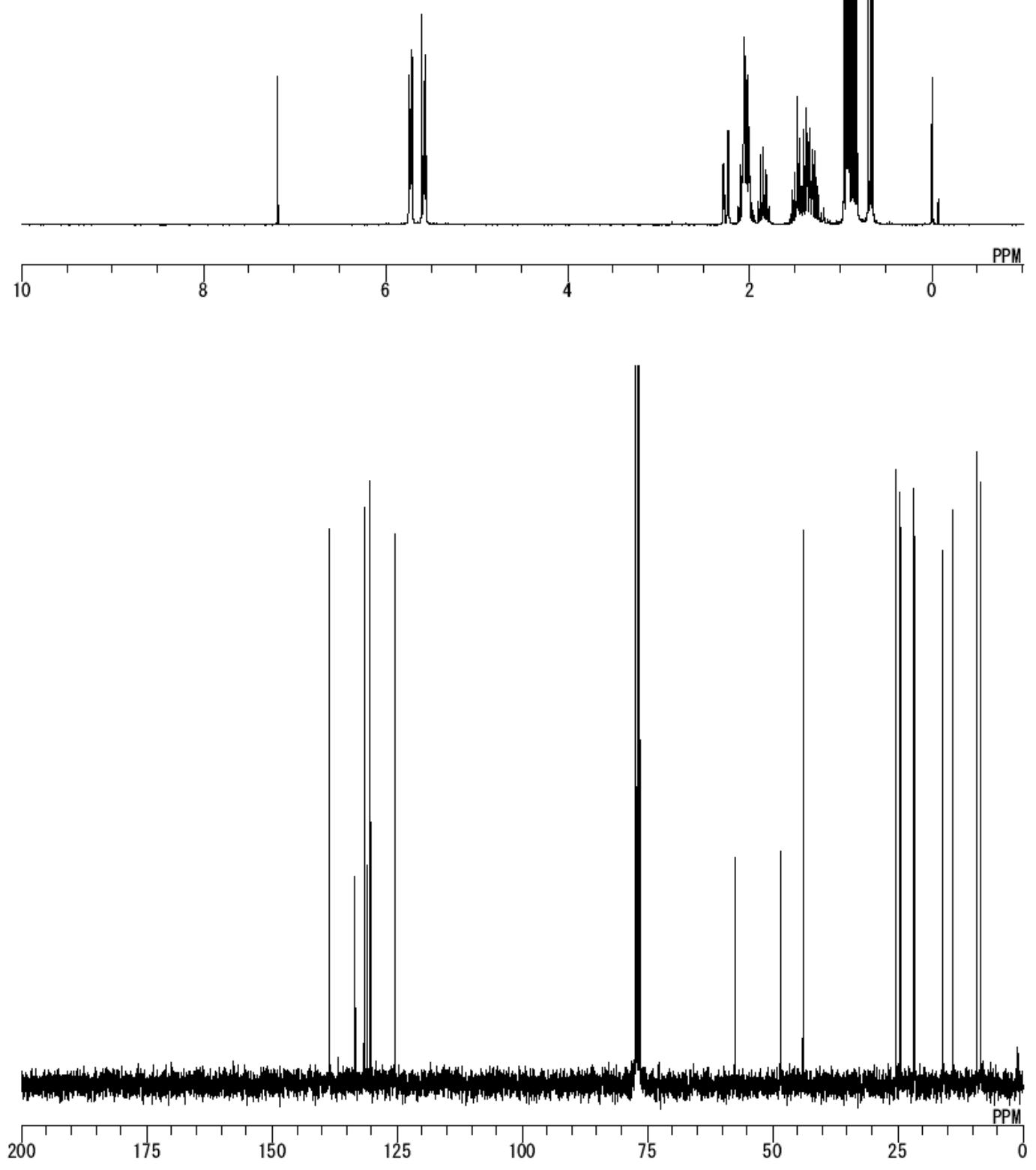

S10 